\title{
"PERO SIGO SIENDO EL REY: MUSIGALIDAD E INTERTEXTUALIDAD DEL RELATO"
}

\author{
Teobaldo A. Noriega \\ (Trent University)
}

\begin{abstract}
RESUMO
O cancioneiro popular mexicano, com sua temática de amores frustrados e mortes, tece o texto de Pero sigo siendo el rey, canção-título que dialoga com quase uma centena de "corridos" e boleros no espaço fictício de Tezontle. O critico Teobaldo Noriega, nesse ensaio, propōe uma audição do romance o que nos permite conhecer a textura musical e os mecanismos do narrador para podermos também participar dessa polifonia da escritura.
\end{abstract}

Ajustándose a una estructura narrativa mediante un discurso que desde el primer momento nos remite a un contexto folclórico-musical mayor, significante cultural de la idiosincracia de un pueblo, Pero sigo siendo el Rey' del colombiano David Sánchez Juliao (1945) se presenta ante todo como un relato que en su múltiple dimensión dialógica ${ }^{2}$ se apropia sistemáticamente de otros discursos con los cuales carnavaliza la realidad que intenta proyectar. Más que una lectura, por lo tanto, mi propósito es proponer aquí una audición de la novela que nos permita apreciar mejor su textura musical, proceso al que sin duda contribuye activamente la complicidad del lector.

La fábula es reducible a una serie superpuesta de aventuras amorosas que inevitablemente acaban en tragedias. Tezontle, el espacio ficticio, es un microcosmos habitado por hombres y mujeres condicionados todos por un rigido código de comportamiento social que determina sus destinos. Un mundo donde las categorias macho/hembra sintetizan

1 JULiaO. David sánchez. Pero sigo siendo el Rey. Bogotá: Plaza 5 Janés. 19B3. 269 p.

2 BAKHTIN. Véase Mikhall. The Dialogic Imagination. Edited by M Holqulst. Austin: Untversity of TexBs Press, 1981. 
los limites de cualquier opción posible, y donde la vida es sólo una pasajera circunstancia cuyo verdadero valor morbosamente lo rescata la heroicidad de la muerte. El correlato que de inmediato se insinúa es el del universo-estereotipo tradicionalmente cantado por el corrido mexicano, referente obligado del dialogismo inherente al texto novelístico y base estructuradora de la musicalidad aludida. El relato se organiza en cuatro movimientos diferentes, precedidos por la partitura de una canción que da título a toda la novela y sirve al mismo tiempo de introducción temática o prólogo. Completados estos movimientos o variaciones sobre un mismo tema (la pasión, el despecho, los celos, el machismo, o el honor maltratado que conduce a la muerte), aparece una coda que cierra el desarrollo textual con una referencia final al leitmotiv de las nefastas palomas rojas en el cielo de Tezontle. Cada uno de los movimientos señalados equivale a momentos específicos de la diégesis total.

En el "Primer Movimiento" (pp. 17-87) el eje del relato lo constituyen las historias de Flor de Azalea-Bronco Reynosa-Adán Corona, y Martín Estrada Contreras-María de la Paz. En el primer caso Flor de Azalea convencida de que su enamorado, el Bronco Reynosa, no regresará al pueblo, acepta contra su voluntad casarse con Adán Corona, nuevo pretendiente impuesto por su padre. Pero el Bronco, que ha estado trabajando en el Norte para cumplir la promesa hecha a sua amada, vuelve el mismo día en que ella está a punto de casarse con el otro y, obedeciendo a su destino de hombre traicionado, mata a los dos. En el segundo caso Martín Estrada Contreras, invencible cazadur de fortunas, trata afanosamente de reconciliar su buena suerte en las barajas con la desdicha de saberse incapaz de satisfacer físicamente a María de la Paz, su apasionada mujer. Un día llega a Tezontle otro tahưr llamado Jesús Cadena en busca de Martín y éste, habiendo sido desposeido de toda su fortuna por el visitante, apuesta por último a su mujer y también la pierde. En un gesto final de hombre que cumple su palabra, Martin entrega su mujer al contrincante, pero se la entrega muerta. Para completar su acto de valor luego se suicida.

Tres historias constituyen el eje relato "Segundo Movimiento" (pp. 91-148): Juan-Micaela Aguilar, Jesus CadenaChabela García, y Casimiro-Anselma. En el primer caso Juan, hermano de la difunta Flor de Azalea, enamorado apasionadamente de Micaela la mata por celos de Simón Reynosa, hermano del Bronco. Por sua parte el afortunado jugador Jesús Cadena sucumbe a los encantos sobrenaturales de Chabela, mujer de carácter conflictivo cuya extraordinaria 
belleza le concede privilegios especiales, como el de ser mimada por sus padres y celosamente custodiada por su hermano, Casimiro. Un incidente violento entre Jesús y Chabela obliga a Casimiro a poner fin a la vida de aquél. No queda claro quién dispara la bala que esa misma noche mata a la guiera Chabela. Con Casimiro en la cárcel pagando condena, los detalles de su idilio con Anselma se desarrollarán después.

En el "Tercer Movimiento" (pp. 151-214) Juan se hace un individuo respetado por su hombria mientras está en la cárcel; allí se encuentra con el asesino de su hermana, el Bronco Reynosa, y cumpliendo el rito de la obligada venganza lo mata. La realidad mágica del mundo de Tezontle permitirá que a su vez el Bronco regrese de la muerte y se vengue de Juan matando a sus padres. En su desordenada vida amorosa, Juan se enreda un día con Martina Martínez, hermana de Onésimo y Adrián Bailón, casada además con Simón Blanco. Convencido de que Martina le ha sido infiel con Juan, Simón la mata. El otro núcleo del relato en esta parte es la continuación de la historia Casimiro-Anselma quien, sin hermanos varones que la defiendan, sufre el asedio de Hipólito Cabrera, Presidente Municipal. Terminada su condena, Casimiro sale de la prisión y se dedica a cuidar la hacienda familiar, a fortalecer su amistad con los hermanos Infante conocidos en la cárcel, y a disfrutar sus amores con Anselma con quien decide casarse. Convencidos los Infante de que esta unión no es aconsejable para Casimiro, matan a los novios cuando éstos se dirigen a la iglesia y de esta manera le salvan al amigo su amenazado honor.

En el "Cuarto Movimiento" (pp. 217-267) Onésimo y Ađrián Bailón Martínez consiguen mejorar su precaria situación económica con el singular invento de una "ruleta de dieciséis calaveras y cuatro rosas, en donde no se apostaba a la vida sino a la muerte, y en donde siempre se ganaba" (p. 218). La intención de éstos, por supuesto, es ahorrar lo suficiente para comprarse una pistola. Entre tanto Simón Blanco llega en la cárcel a un arreglo con Hipólito Cabrera a quien ahora le interesa la indomable Rosita Alvirez, prima de Simón. Juan Charrasqueado por su parte sigue su vida libertina y en ella arrasa con tres flores (Flor de Canela, Flor Silvestre, y Flor de Albahaca), olvidándose del peligro que en este caso representaban siete hermanos. A sua vez Juan Luis y José Manuel Infante, salidos de la dárcel, se enamoran sucesivamente de la misma mujer, Chabela Rosales, mejor conocida en el pueblo como La Llorona. Los núcleos del relato tienen todos la conclusión esperada: los Martínez matan a Simón Blanco cumpliendo su venganza y trece días después inexplicablemente mueren en sus celdas respectivas; 
los siete hermanos de las tres flores matan a Juan; los Infante se eliminan en un duelo que tienen a causa de La Llorona; y el Presidente Municipal termina por matar de tres certeros disparos a sua deseada Rosita. El, en efecto, es el puente necesario entre el movimiento final y la introducción del tema al exclamar: "Pero sigo siendo el Rey" (p. 267), motivo que se hace eco del título de la novela y de la partitura musical inicialmente expuesta por el prólogo.

$\mathrm{Si}$ bien es cierto que mi intención no es establecer un paralelo exacto entre la disposición sinfónica insinuada por el subtítulo de esta obra y la estructura verbal que la contiene", he sugerido no obstante una analogía entre un momento de audición o escucha y la experiencia del lector al enfrentarse a este texto. Aceptando las inevitables limitaciones que en este caso se imponen, intentaré puntualizar esta idea no sin antes recordar la acertada observación de Melvin Friedman relacionada con la diferencia que existe entre proceso musical y proceso literario:

There is no exact correspondence between the written word and the musical chord. While two words may never be pronounced at the same time without confusion, more than one musical note may be played or sung simultaneously and with equal loudness. Nor is there an exact literary equivalent of the counterpointing of two independent melodies. When the writer tries to counterpoint different themes, however rapidly he makes them interWeave and overlap, they still have the quality of alternating successively rather than occurring at the same time. But he may hit upon certain devices which give a convincing illusion of the same effect".

Es evidente que en Pero sigo siendo el Rey se logra un alto grado de musicalidad precisamente gracias a diferentes mecanismos internos y externos que sirven de apoyatura a

3 Como bien lo atestigua la critica literaria, tal intento constituye desde hace tiempo objeto de experimentación y búsquedas en la histirla de la novela como género (algunos ejemplos: Freedman, w. Lauremce Sterne and the Origins of tho Musical Novel, Athens: University of Georgla Press, 1978; Matoré, G. e Mecz, I. Musiqua et structure romanesque dans A la recherche du temps perdu, Strasbourg: Editions Klincksieck, 1972; Bowen, Z. Musical Allusions in the Works of James Jayce, Albany: State University of N.Y. Press, 1984), con resultados estéticamente satisfactorios como lo demuestran los estudios mencionados. Fs evidente que en el caso de sánchez Juliao se trata esencialmente de un proceso de carnavalización que, basándose acertadamente en el humor implicito del texto, hace referencia a una realidad que en la experiencia del lector queda musicalmente expresada.

4 Friedman, M. Stream of Consciousmess: a studyin literary method. New Haven: Yale University Press, 1955, p. 124-125. 
las múltiples voces que participan en la polifonia total creada por Sánchez Juliao. Mi punto de partida, como se ve, es conceptualmente bakhtiniano, definiendo la heteroglosia narrativa como una serie superpuesta de perspectivas o voces a través de las cuales el lector descubre determinada imagen de realidad a la cual la escritura lo conduces. El mecanismo interno que sin duda sobresale en la conformación de esa polifonía es el montaje de los diferentes discursos que participan en el relato. Veámoslo en la primera parte del "Primer movimiento":

\section{Voz Ubication Tipo de discurso}

1. ${ }^{2}$ Pág. 17 Narrador mítico que abre la historia $\mathrm{y}$ sintetiza en la imagen de las palomas rojas el cumplimiento trágico de cierta profecía alegórica

$2 .^{2} \quad 17-21$ Narrador básico: Flor-Adán-Bronco

3." 21 Solo (discurso interior) del Bronco $>$ a Flor

4." 21-22 Dío Flor/Bronco, en flashback

5. 22 Solo (discurso interior) de Flor > al Bronco

4." 22 Dúo Flor/Bronco, en flashback

3." 22-23 Solo (discurso interior) del Bronco $>$ a Flor

2." 23-25 Narrador básico: Adán Corona despechado

6. 25 Dúo Adán Casimiro, en la barberia

7." 26 Solo (discurso interior) de Adán > a Flor

6. 26 Dúo Adán/Casimiro, en la barbería

7. 26 Solo (discurso interior) de Adán

6." 26-27 Dúo Adán/Casimiro, en la barbería

$7 .^{3} \quad 27$ Solo (discurso interior) de Adán > a F'lor

8. 27-28 Dro Adán/su madre, en flashback (esc. telescópica)

6. 28 Dío Adán/Casimiro, en la barberia

7. 28 Solo (discurso interior) de Adán > a Filor

6. 28 Dúo Adán/Casimiro, en la barberia

2. 28.30 Narrador básico: Martín Estrada derrota a Adán

5 Para este Importante concepto aportado M. Bakhtin véase su Problems of Dostoevaky's, poetics, Edited and translated by C. Emerson. Minneapolis: University of Minnesota Press. 1984, esveclalmente ol primer capitulo. 
3. 31 Solo (discurso interior) del Bronco $>$ a Flor

9. 31 Dúo Bronco/alguien que le ayudará a cruzar frontera

3. 31 Solo (discurso interior) del Bronco $>$ a Flor

4. 31.32 Dúo Flor /Bronco, en flashback

$9 .^{2} \quad 32$ Dúo Bronco/alguien que le ayudará a cruzar frontera

$3 .^{a} \quad 32$ Solo (discurso interior) del Bronco $>$ a Flor

9. 32 Dúo Bronco/alguien que lo ayudará a cruzar frontera

$4 .^{a} \quad 33$ Dúo Flor/Bronco, en flashback

$3 .^{2} \quad 33$ Solo (discurso interior) del Bronco $>$ a Flor

10. 33 Trio Bronco/policia de frontera/otro hombre

$3 .^{\mathrm{a}} \quad 33$ Solo (discurso interior) del Bronco $>$ a Flor

10. 34 Trio Bronco/policia de frontera/otro hombre

3. 34 Solo (discurso interior) del Bronco $>$ a Flor

2. $\quad$ 34-36 Narrador básico: Juan se enamora de Micaela Aguilar

11.a 36 Dúo Juan/Adán

$12 .^{\mathrm{a}} \quad 36.37$ Solo (discurso interior) de Flor $>$ a Ađán Corona

11. 37 Dúo Juan/Adán

12. 37 Solo (discurso interior) de Flor $>a$ Adán Corona

13. 37 Dúo Adán/don Baltasar (esc. telescópica)

12. 38 Solo (discurso interior) de Flor $>$ a Adán Corona

14. 38 Solo (discurso interior) de Adán

12. 38 Solo (discurso interior) de Flor $>a$ Adán Corona

11." 38-39 Dúo Juan/Adán

$1 .^{\mathrm{a}} \quad 39$ Narrador mitico que reitera el motivo inicial

Junto a la alternancia de voces ( 13 voces y 43 secuencias en el montaje anterior correspondiente a una minima parte del texto total), mecanismo sistematizado por el relato para conformar el macrodiscurso respectivo, podemos anotar 
tres procedimientos internos directamente relacionados con la musicalidad sugerida: la repetición sintática, la suspensión del discurso, y el contrapunto narrativo. En el primer caso se establece una línea de percusión acuistica nitidamente percebida por el oyente en el proceso de lectura. Puede tratarse de la seriación en eco de un mismo tiempo verbal; como cuando el narrador básico dice de Casimiro que, a fin de estar siempre al lado de su hermana: "hacia de guardarropas tras bambalinas... exigia bailar con ella... hacía de cordero manso cuando actuaba de pastorcita... y representaba a Dios en los altares" (p. 112). O cuando describe el momento que sigue a la muerte de Martina, matada por Simón Blanco: "La paloma blanca abandonó el alféizar y se lanzó al aíre... voló sobre el jardín... contempló desde la altura los hatos... pasó sobre el arroyo... entró con el toque de campanas... y descendió con lentitud sobre una alcayata de la Presidencia Municipal" (p. 207-208). Alcanzando por supuesto con la aliteración su máximo grado de armonía en un ejemplo como el siguiente donde el narrador trata de resaltar la unidad formada por el inseparable trío CasimiroJuan Luis-José Manuel Infante:

Golpeaban las tres mismas bolas en los tres mismos salones de billar, bebian las tres mismas marcas de tequila en las tres mismas cantinas, compraban el mismo amor desalentado a las tres mismas pirujas en las tres mismas casas de faroles rojos, y se burlaban de las tres mismas personas en las tres mismas historias tres mil veces repetidas (213).

La suspensión lineal del discurso es igualmente un mecanismo constante en el que se apoya la alternancia de voces ya indicada. Su estructuración más frecuente es la de un discurso interior o soliloquio' (A), con interrupciones (B. C) enmarcadas por el hilo o linea melódica central (A), de lo que resultan con frecuencia combinaciones de estos tipos: ABACACA; ABABABA; ABACBACABACA. En relación orgánica con la intertextualidad que da vida al macrodiscurso, la suspensión es también el mecanismo utilizado por el texto al apropiarse o citar constantemente el cancionero mexicano e hispanoamericano. Por último, el contrapunto narrativo ${ }^{\overline{ }}$, sienđo un procedimiento de tipo estructural tiene

6 Stro aquf la definición de soliloquio aportade por Robert Humphrey en su estudio Stream of consciousness in the modern novel. Berkeley: Uniretsity of Callorna Press. 1955. p. 36.

7 Para entender mejor los límites de la posible analogia contrapunto musical/contra. punto narrativo, véase el estudio de M.Friedman, Stream of consciousmess, en cspeclal el capltulo quinto, "The analogy Fith music", 121-138. 
consecuencias inmediatas en la musicalidad de la historia orquestada ya que al oponer o contrastar dos líneas diferentes del discurso intensifica con ello su sonoridad. Esto se nota, por ejemplo, al iniciarse el "Segundo Movimiento", momento de la historia en que el lector tiene la impresión de asistir al velorio de Flor de Azalea y participar en el ritual. Lo que el contrapunto resalta es la oralidad expresiva de esa situación (en este caso desacralizada), y el resultado es de evidente naturaleza ritmico-musical:

- Virgo Clemens...

- Ora pro nobis.

- Luz del sendero de mis noches sin fortuna...

- Ora pro nobis.

- Aretes que le faltan a la luna...

- Ora pro nobis.

- Espinita que se me ha clavado en el corazón...

- Ora pro nobis.

- Mañanita del rey David...

- Ora pro nobis.

- Rosa deslumbrante, divina rosa que encendió mi amor...

- Ora pro nobis (p.91).

Situación que a su vez tiene su correspondiente contrapuntístico externo en el "Tercer Movimiento", cuando de nuevo el lector es invitado a participar en el ritual del velorio de Chabela:

- Virgo Clemens...

- Ora pro nobis.

- Paloma querida que llegaste a mi vida...

- Ora pro nobis.

- Cielito lindo que alegras los corazones...

- Ora pro nobis.

- Viento sagrado que corre alrededor de este mundo...

- Ora pro nobis.

- Reina de divinos ojos verde jade...

- Ora pro nobis.

- Amor que me comprende y que siento que me quiere más que nadie...

- Ora pro nobis (p. 155).

Si por una parte tanto el montaje polifónico como los mecanismos internos del relato apuntan directamente a su carácter musical, no cabe duda igualmente que los abundan. 
tes indicadores externos son expresión concreta de lo que Sánchez Juliao se ha propuesto hacer. Recordemos que la novela tiene como subtítulo "Sinfonía para lector y mariachi, opus 1",8 y que inmediatamente antes de la partitura que sirve de prólogo aparecen dos páginas que anuncian el con. cierto; el grupo de artistas participantes lo forman los diferentes personajes cuyas voces o actuaciones, asi como las de "otro magnífico elenco de estrellas de la canción" (p. 11), el lector escuchará a lo largo del texto; los créditos musicales señalan nombres muy conocidos entre los que figuran José Alfredo Jiménez (de él es la canción que da título a la novela), La Tariácuri, Cuco Sánchez, y Chabuca Granda; por último, y sin dejar posibilidad alguna de sorpresa, el responsable de la dirección general es un señor llamado David Sánchez Juliao. La novela se presenta, pues, como un espetáculo musical dividido en cuatro partes a las que corresponde un movimiento especifico: allegro cantabile, allegretto scherzando, tempo di menuetto, y allegro vivace. Las imágenes que acompañan al anuncio de cada uno de estos movimientos (la muerte dialogando o cantando) son el telón de fondo que refuerza la teatralidad del concierto, y la coda su punto final. Participantes todos en el espetáculo anunciado, los personajes cumplen con su obligación: cantan; de ahí el dinámico tráfico intertextual mantenido por Pero sigo siendo el Rey con el cancionero popular mexicano e hispanoamericano.

El dialogismo sostenido por el texto novelístico a este nivel se obtiene principalmente de tres maneras: 1) en algún momento del relato un personaje canta una canción determinada; 2) la letra de una canción es directamente absorvida o citada" por el discurso del personaje; y 3) el personaje de una canción forma parte ya de la diégesis novelística dentro de la cual se desarrolla su drama particular al que alude la canción. El primero de estos casos es el más evidente y por lo mismo no necesita mayor explicación; sirvan de ejemplos el corrido que canta el Bronco Reynosa al regresar a Tezontle (p. 80-82), la canción que canta José Manuel Infante en casa de don Esteban (p. 167), o la que le canta en ausencia Rosita Alvírez al Presidente Municipal (p. 260-263). La complicidad del lector es requisito indispensable en el segundo caso

B Aunque se ha sugerido que esta novela es la primera parte de una trilogla relacionada can la música popular de América Latina. Mi sangre aunaue plebeya. Bogota: Planeta, 1986. segunda parte de la trllogia, sjgue de clerta forma una línea diferente aunque el título $\mathrm{J}$ la portada las emparentan. Una mejor evaluacíón rodremos hacer cuando aparezca la tercera parte.

9 Para este cancepto vébse. por ejemplo. Graciela Reyes. Polifonfa toxtual. La citación en el relato literario. Madrid: Editorial Gredos. 1984. especialmene los capltulos primero y segundo. 
puesto que solamente él puede detectar, seguir y completar el texto de la canción absorvida, a partir de su propia expe. riencia o familiaridad con el cancionero popular. Asi, por ejemplo, cuando Adán Corona ("Primer Movimiento", episodio de la barberia) se distrae en su solo dirigido a Flor, y dice: "Tengo dinero en el mundo, dinero maldito que nada vale. . Yo para que quiero riqueza si voy con el alma perdida y sin fe" (p. 26-28), lo que el lector-oyente reconoce de inmediato - a pesar de las interrupciones conferidas a ese nivel del discurso - es la conocida canción "La que se fue", dispersa y camuflada a lo largo del discurso mayor que la asimila. Cuando en su solo a Micaela ("Segundo Movimiento") Juan le dice entre otras cosas: "Solamente la mano de Dios podrá separarnos, ya que nuestro amor es más grande que todas las cosas del mundo..." (p. 103), de nuevo el lector reconoce la canción "La mano de Dios" como el texto asimilado. El procedimiento es utilizado con tal frecuencia que los abundantísimos ejemplos superarían los limites del presente trabajo. Finalmente, y constituyendo el mecanismo más elaborado, la novela no solamente incorpora a su estructura musical el texto de una canción sino que se convierte asimismo en actualización de esa historia. Si pensamos nuevamente en la analogia establecida con un espectáculo, lo que cada personaje de la novela hace es representar y cantar su propio drama: Flor de Azalea, Juan Charrasqueado, Juan Luis y José Manuel Infante, Martina Martínez, Simón Blanco, Onésimo y Adrián Bailón, Rosita Alvirez, y La Llorona, entre otros, son personajes históricos o legendarios cuyas existencias - ya codificadas por una tradición folclórica popular son aquí rescatadas por el marco dialógico de la ficción. $\mathrm{Si}$ en su sentido amplio intertextualidad quiere decir transposición de un sistema de signos en otro ${ }^{10}$, lo que Sánchez Juliao hace en esta novela es, como acabamos de ver, apropiarse de un sistema ya existente de significantes a partir del cual estructura hábilmente su macrodiscurso: la escritura como una re-escrita. Un ejemplo más de la vitalidad que caracteriza a la novelística colombiana de los últimos años en su constante búsqueda de nuevas direcciones.

10 Aparte de las Ideas apartadas directamente por Bakhtin al respecto. ampliadas a su vez por los estudlos da Julia Kristeva, entre atros, una buena contribuctón a la puesta cn práctica de este concepto como método de análisis cs intertoxtuality. New perspocives in eriticism. NeF York: New Yos/ Literary Forum, 1978 donde el cnfonue plurldimensolnal permite apreciar mejor la riqueza de posibllida. des que su aplicaclón ofrece. 